\title{
A New Approach to Cure and Reinforce Cold-Cured Acrylics
}

\author{
Yat Cheong So $\cdot$ James Kit-Hon Tsoi • \\ Jukka P. Matinlinna
}

Received: 27 December 2011 / Accepted: 9 May 2012 / Published online: 24 May 2012

(C) The Author(s) 2012. This article is published with open access at Springerlink.com

\begin{abstract}
Purpose The low degree of polymerization of coldcured acrylics has resulted in inferior mechanical properties and fracture vulnerability in orthodontics removable appliances.

Methods In this study, the effect of reinforcement by various concentrations of chopped E-glass fibers $(0 \%$, $1 \%, 2 \%, 3 \%$ and $5 \%$ by weight of resin powder) and post-curing microwave irradiation ( $800 \mathrm{~W}$ for $3 \mathrm{~min}$ ) on the flexural strength of cold-cured acrylics was evaluated at various storage conditions (at room temperature for 1 day and 7 days; at water storage for 7,14 and 30 days).

Results The data was analyzed by using 1-way and 2way ANOVA, and a Tukey post hoc test $(\alpha=.05)$. The specimens with chopped E-glass fibers treated with post-curing microwave irradiation significantly increased the flexural strength of cold-cured PMMA. The optimal concentration might be $2 \%$ fibers under irradiation.

Conclusions The exhibited reinforcement effect lasted in a consistent trend for 14 days in water storage. A new fiber-acrylic mixing method was also developed.
\end{abstract}

Y. C. So · J. K.-H. Tsoi $(\bowtie)$ · J. P. Matinlinna

Dental Materials Science, Faculty of Dentistry, University of Hong Kong, Hong Kong SAR, China

e-mail: jkhtsoi@hku.hk

\section{J. K.-H. Tsoi}

Prince Philip Dental Hospital,

Room 4A15, 4/F, 34 Hospital Road,

Sai Yin Pun, Pokfulam, Hong Kong
Keywords Denture based materials • Cold-cured acrylics $\cdot$ E-glass fibers $\cdot$ Microwave irradiation • Fiber-acrylic mixing method

\section{Introduction}

Acrylic resin poly(methylmethacrylate) (PMMA) was introduced as a denture base polymer in the late 1930s and it gained popularity due to its low cost, easy manipulation, satisfactory appearance and dimensional stability $[1,2]$. To initiate the polymerization of methylmethacrylate (MMA), a free radical mechanism generated by benzoyl peroxide is involved, and this initiation step may be activated by heat or by chemicals such as $N, N$-dimethyl- $p$-toluidine. The PMMA product that requires heat for activation is named heatcured PMMA, whereas cold-cured PMMA or autopolymerized PMMA refers to the product that is chemically activated [3]. Usually, heat-cured PMMA is used as the so-called "gum-work" for removable full dentures or removable partial dentures [4]; the cold-cured PMMA is used for denture repair, reline and orthodontic removable appliances involved in thumb deterrent, tipping teeth, block movements, overbite reduction, space maintenance and retention [5-7].

The degree of polymerization (DP) in cold-cured PMMA is low. Thus, inferior mechanical strength is exhibited and the low DP leads to more unreacted MMA monomers than for heat-cured PMMA [3, 8]. In the challenging oral environment in which PMMA is subjected to interact with endogenous substances including saliva with its enzymes, proteins, polysaccharides and bacteria, and exogenous substances from the dietary intake; water sorption also from saliva; 
shear and compression forces generated by chewing action, as well as thermal and chemical fluctuation during dietary intake. Thus, changes in the chemical, physical and biomechanical properties of PMMA are expected [9]. Therefore, cold-cured PMMA is more vulnerable to fracture. In a randomized trial study, it was found that the survival rate in one year of both maxillary and mandibular Hawley retainers was about $70 \%$, with fractures as the major reason for failure and thus the need for reinforcement of acrylic retainers was suggested [10].

Although several methods are advocated to reinforce PMMA, there are advantages and disadvantages for each method. For example, incorporation of a low-molecular-weight polybutadienestyrene rubber was suggested to enhance the impact strength of PMMA without compromising the Young's modulus, viscoelastic properties and viscosity [11]. However, the high cost of rubber is a major concern [12]. Metal inserts such as stainless steel and brass in the form of wires, plates, lingual bars and meshes are another reinforcing methods and had shown them to increase the transverse strength $[13,14]$. Given this, the inserts treated with some surface treatments, such as sandblasting and a silanizing technique, were demonstrated to elevate the fracture resistance $[15,16]$. Even so, carbon fibers in strand and woven mat form might also be added into PMMA for reinforcement [17]. Nevertheless, carbon fibers are very difficult in handling and polishing. The aesthetic issue of the black color and the potential toxicity also has limited the use of carbon fibers [12]. Aramid fibers have exhibited the capability of increasing the impact strength and transverse strength of PMMA [18, 19]. However, mucosal irritation and discomfort [19] and the inherent yellow color are problematic [12]. Ultra-high molecular weight polyethylene (UHMWPE) fibers were also suggested as reinforcing materials for PMMA, but there remains the lack of effective bonding to PMMA [20]. On the other hand, UHMWPE fibers reduced the water sorption and dimensional changes of PMMA [21].

Given this, glass fibers seem to be the most suitable reinforcing materials for PMMA due to the proven enhancement in its mechanical properties [22-29]. Glass fibers are predominantly made of silicon dioxide, with the addition of some other metal oxides. The bonding is effective to PMMA after silanization [30,31] and good embedding of PMMA to the polymer-preimpregnated glass fibers $[23,32,33]$. In the fabrication of orthodontic retainers using cold-cured PMMA, the so-called "sprinkle method" is often employed to construct the appliance. It involves dispensing the monomers and polymers directly onto the working model [34]. Us- ing chopped glass fibers incorporated into the resin powder-monomer liquid mixture might be the most compatible method for reinforcement [35]. However, chopped glass fibers were shown to deliver a limited reinforcement effect [24]. Due to this limitation, extra treatment of cold-cured PMMA together with chopped glass fiber may achieve a more potential effect than the sole treatment on reinforcement. Microwave irradiation at the post-curing stage of cold-cured PMMA might be an appropriate option. A study has shown that post-curing microwave irradiation of pure coldcured PMMA improved the fracture toughness and the Vickers hardness [36]. Moreover, it was reported that the microwave treatment influenced the stronger bonding at the glass fiber-epoxy resin interface [37].

To date, there are no studies demonstrating the effect of combining chopped glass fibers reinforcement and post-curing microwave irradiation on the mechanical properties of cold-cured PMMA. Thus, the aim of this in vitro study was to determine the effect of various concentrations of chopped E-glass fibers on the flexural strength of cold-cured PMMA with post-curing microwave irradiation.

\section{Materials and Methods}

\subsection{Specimen Preparation}

In this study, 50 test groups, each contains randomly assigned 12 beam-shaped specimens, were used for flexural strength testing according to Table 1 . The required materials are silanized E-glass fibers (Ahlstrom Fibreglass Ltd, Karhula, Finland, Lot No. R3382400/V/P) and cold-cured PMMA (Ivoclar Vivadent, Schaan, Liechtenstein, Lot No. K43271) for specimen preparation. The manufacturer recommended usage instruction and compositions are listed at the Table 2.

Firstly, silanized E-glass fibers were chopped into $3 \mathrm{~mm}$ long chopped fibres using a cutting blade. Then, the required weight of chopper fibers (as $0 \%, 1 \%$, $2 \%, 3 \%$ and $5 \%$ by weight to $20.50 \mathrm{~g}$ powder) was wetted with $7.50 \mathrm{ml}$ methyl methacrylate, MMA, liquid which can adequately prepare 12 specimen beams for each test group. Chopped E-glass fibers, which were in bundles, were spread and carefully agitated manually to ensure proper wetting. After that, $0.500 \mathrm{~g}$ of the powder was added into the liquid and stirred for $10 \mathrm{~s}$ to form a mixture; this step was repeated for 6 times, i.e. the powder was added as increments to ensure a proper blending. Further stirring of the mixture for 2 min was required to ensure proper embedding of chopped fibers into the MMA matrix. The fibers were then found 
Table 1 Grouping of specimens and number of specimens in each study group

\begin{tabular}{|c|c|c|c|c|c|c|}
\hline $\begin{array}{l}\text { Fiber } \\
\text { concentration } \\
\text { (by wt-\% of } \\
\text { PMMA } \\
\text { resin) }\end{array}$ & Treatment & $\begin{array}{l}\text { Storage } \\
\text { at room } \\
\text { temperature } \\
\text { and ambient } \\
\text { humidity for } \\
1 \text { day }\end{array}$ & $\begin{array}{l}\text { Storage } \\
\text { at room } \\
\text { temperature } \\
\text { and ambient } \\
\text { humidity for } \\
7 \text { days }\end{array}$ & $\begin{array}{l}7 \text { days in } \\
\text { water storage }\end{array}$ & $\begin{array}{l}14 \text { days in } \\
\text { water storage }\end{array}$ & $\begin{array}{l}30 \text { days in } \\
\text { water storage }\end{array}$ \\
\hline \multirow[t]{2}{*}{$\overline{0}$} & No microwave & 12 & 12 & 12 & 12 & 12 \\
\hline & With microwave & 12 & 12 & 12 & 12 & 12 \\
\hline \multirow[t]{2}{*}{1} & No microwave & 12 & 12 & 12 & 12 & 12 \\
\hline & With microwave & 12 & 12 & 12 & 12 & 12 \\
\hline \multirow[t]{2}{*}{2} & No microwave & 12 & 12 & 12 & 12 & 12 \\
\hline & With microwave & 12 & 12 & 12 & 12 & 12 \\
\hline \multirow[t]{2}{*}{3} & No microwave & 12 & 12 & 12 & 12 & 12 \\
\hline & With microwave & 12 & 12 & 12 & 12 & 12 \\
\hline \multirow[t]{2}{*}{5} & No microwave & 12 & 12 & 12 & 12 & 12 \\
\hline & With microwave & 12 & 12 & 12 & 12 & 12 \\
\hline
\end{tabular}

to be finely dispersed in the mixture and a pale blue color of the mixture was observed; however, its role or significance was not studied further. The pale blue color remained until the next preparation step.

The remaining required resin powder (i.e. $17.00 \mathrm{~g}$ ) was added into the viscous mixture of chopped E-glass fiber and PMMA blend, followed by the addition of the remaining MMA liquid $(2.50 \mathrm{ml})$. After that, the mixture was mixed thoroughly for $1 \mathrm{~min}$ to ensure that a fine dough-like consistency was formed. To prepare the specimen beams $(45.5 \mathrm{~mm} \times 4.5 \mathrm{~mm} \times 6.5 \mathrm{~mm})$, the thoroughly mixed dough was packed into the stainless steel mold (which was first coated with a thin layer of Vaseline for easy detachment of the set of specimen beams) and then kept by a clamp at a pressure of 23 bar for $30 \mathrm{~min}$. Finally, all beams were detached from the mold.

Next, for the specimens that required post-curing microwave irradiation, they were detached from the stainless steel mold and immediately treated in a microwave oven (Panasonic, NN-S215WF) at $800 \mathrm{~W}$ (high power) for $3 \mathrm{~min}$. Three specimens were held in a microwavable plastic box $(20 \mathrm{~cm} \times 10 \mathrm{~cm} \times 5 \mathrm{~cm})$ and
2 boxes were placed into the microwave oven for each time.

\subsection{Specimen Aging}

Upon the completion of the specimen preparation, 360 specimens were immersed in water for storage according to Table 1 . Six specimen beams (1 set) were fully covered by $80 \mathrm{ml}$ deionized water in a plastic beaker. The plastic beaker was covered with a plastic wrap and stored in an incubator at a constant temperature of $37^{\circ} \mathrm{C}$ and with $99 \%$ humidity. The water storage times were 7,14 and 30 days. As for the control, remaining 240 specimens were also stored at room temperature $\left(21^{\circ} \mathrm{C}\right)$ and at a constant humidity $(76 \%)$, for 1 day and 7 days; this was done in order to examine the effect of water storage on the flexural strength of the reinforced PMMA specimens.

\subsection{Testing the Specimens}

A universal testing machine (ElectroPuls ${ }^{\mathrm{TM}}$ E3000, Instron Industrial Products, Grove City, PA, USA)

Table 2 Materials used in the study

\begin{tabular}{|c|c|c|c|c|}
\hline Material & Manufacturer & Lot number & Usage instruction & Composition \\
\hline $\begin{array}{l}\text { Silanized E-glass } \\
\text { fiber }\end{array}$ & $\begin{array}{l}\text { Ahlstrom } \\
\text { Fibreglass Ltd, } \\
\text { Karhula, } \\
\text { Finland }\end{array}$ & R338-2400/V/P & N/A & A silane, E-glass \\
\hline $\begin{array}{l}\text { Cold-cured PMMA } \\
\text { Product Name: } \\
\text { ProBase Cold }\end{array}$ & $\begin{array}{l}\text { Ivoclar } \\
\text { Vivadent, } \\
\text { Schaan, } \\
\text { Liechtenstein }\end{array}$ & K43271 & $\begin{array}{l}\text { Mixing ratio: } \\
20.5 \mathrm{~g} \text { powder/ } \\
10.0 \mathrm{ml} \text { liquid } \\
\text { (for preparation } \\
\text { of } 12 \text { specimens) }\end{array}$ & $\begin{array}{l}\text { Powder: Polymethyl methacrylate, } \\
\text { softening agent, benzoyl peroxide, } \\
\text { catalyst, pigments } \\
\text { Liquid: Methyl methacrylate, } \\
\text { dimethacrylate, catalyst }\end{array}$ \\
\hline
\end{tabular}


was employed for the three-point bending tests. The span length between 2 supports was $20.0 \mathrm{~mm}$ and the crosshead speed was $1.0 \mathrm{~mm} / \mathrm{min}$ during loading. Load and deflection were recorded with Console software (Instron Industrial Products) and the load-deflection curves were plotted. The maximum load was applied to formula (1) to calculate the flexural strength of these rectangular beams:

$\mathrm{O}=\frac{3 \mathrm{FL}}{2 \mathrm{bh}^{2}}$

where

Ó Flexural strength in three-point bending

F Maximum load on the load-deflection curve

L Span length between two supports

b Width of the specimen

$\mathrm{h}$ Height of the specimen

\subsection{Statistical Analysis}

The mean value and the standard deviation of the flexural strength in each test group were calculated and statistically analyzed by using software Predictive Analytics SoftWare (PASW) Statistics 18.0 (Statistical Package for Statistical Science Inc., Chicago, IL, USA). The level of statistical significance $\alpha$ was set at 0.05 . 1-way ANOVA and the Tukey multiple comparisons post hoc analysis were performed $(p<0.05)$ to compare the testing groups in different water storage days. 2-way ANOVA was also applied to determine the main significant effects of fiber concentration and microwave irradiation, and the interaction effect of fiber and microwave irradiation.

\subsection{Failure Mode Analysis}

Fractured specimens from each test group were selected for investigation of fracture surfaces using scanning electron microscopy. Samples were fixed on aluminum sample holders, and then sputtered with gold in an ion sputter device (JFC-1100, JEOL, Tokyo, Japan). Samples were then examined by taking images with a scanning electron microscope (XL30CP Philips, Eindhoven, The Netherlands) for fracture morphology, adhesion and embedding of fibers into the PMMA matrix.

\section{Results}

The mean values and standard deviations for the tested specimens are shown in Table 3, and in Figs. 1, 2, 3, 4 and 5.

For the storage condition at room temperature and humidity for 1 day, the group with $3 \%$ fiber and microwave treatment $(p=0.003)$, and the groups with $5 \%$ fiber regardless of microwave treatment ( $p \leqq 0.003)$ exhibited a significant increase in the flexural strength values compared with the control group. After the storage at room temperature and humidity for 7 days, all groups except the non-microwave treated specimen in $1 \%$ and $2 \%$ fiber concentration were found to have a flexural strength higher than the control group. After water storage for 7 days, the number of specimen groups that exhibited the reinforcement effect decreased compared with storage condition at room temperature and humidity for 7 days: for non-microwave treated groups,

Table 3 The mean value and standard deviation of flexural strength (MPa) of the test specimens

\begin{tabular}{|c|c|c|c|c|c|c|}
\hline $\begin{array}{l}\text { Fiber } \\
\text { concentration } \\
\text { (by wt-\% of } \\
\text { PMMA resin) }\end{array}$ & $\begin{array}{l}\text { Microwave } \\
\text { treatment }\end{array}$ & $\begin{array}{l}\text { Storage } \\
\text { at room } \\
\text { temperature } \\
\text { and ambient } \\
\text { humidity for } \\
1 \text { day }\end{array}$ & $\begin{array}{l}\text { Storage } \\
\text { at room } \\
\text { temperature } \\
\text { and ambient } \\
\text { humidity for } \\
7 \text { days }\end{array}$ & $\begin{array}{l}7 \text { days water } \\
\text { storage }\end{array}$ & $\begin{array}{l}14 \text { days water } \\
\text { storage }\end{array}$ & $\begin{array}{l}30 \text { days water } \\
\text { storage }\end{array}$ \\
\hline \multirow[t]{2}{*}{0} & No microwave & $77.37 \pm 8.26$ & $73.34 \pm 12.26$ & $71.68 \pm 8.23$ & $75.34 \pm 7.80$ & $72.36 \pm 8.00$ \\
\hline & With microwave & $84.53 \pm 13.84$ & $86.97 \pm 9.51$ & $82.95 \pm 5.11$ & $80.51 \pm 9.64$ & $72.53 \pm 10.33$ \\
\hline \multirow[t]{2}{*}{1} & No microwave & $77.00 \pm 9.81$ & $71.26 \pm 9.25$ & $71.93 \pm 8.17$ & $80.24 \pm 4.64$ & $64.40 \pm 11.22$ \\
\hline & With microwave & $87.08 \pm 7.42$ & $91.68 \pm 8.98$ & $75.33 \pm 7.27$ & $80.26 \pm 6.79$ & $78.00 \pm 6.28$ \\
\hline \multirow[t]{2}{*}{2} & No microwave & $81.81 \pm 7.01$ & $79.52 \pm 7.86$ & $77.66 \pm 4.95$ & $80.52 \pm 6.10$ & $79.59 \pm 5.70$ \\
\hline & With microwave & $86.86 \pm 7.49$ & $93.24 \pm 4.87$ & $82.66 \pm 9.69$ & $87.18 \pm 7.96$ & $78.16 \pm 9.62$ \\
\hline \multirow[t]{2}{*}{3} & No microwave & $80.36 \pm 6.23$ & $84.94 \pm 4.52$ & $80.79 \pm 2.42$ & $86.64 \pm 4.86$ & $76.60 \pm 9.15$ \\
\hline & With microwave & $92.19 \pm 6.90$ & $95.52 \pm 3.95$ & $83.59 \pm 7.96$ & $83.15 \pm 8.85$ & $83.25 \pm 6.09$ \\
\hline \multirow[t]{2}{*}{5} & No microwave & $92.33 \pm 7.01$ & $91.77 \pm 5.70$ & $86.93 \pm 5.14$ & $80.64 \pm 8.47$ & $75.55 \pm 5.38$ \\
\hline & With microwave & $95.39 \pm 7.99$ & $98.60 \pm 10.68$ & $90.41 \pm 7.11$ & $83.11 \pm 8.18$ & $83.34 \pm 6.22$ \\
\hline
\end{tabular}




\section{Flexural Strength (MPa)}

Flexural Strength of Specimen Stored at Room Temperature and Humidity for 1 Day

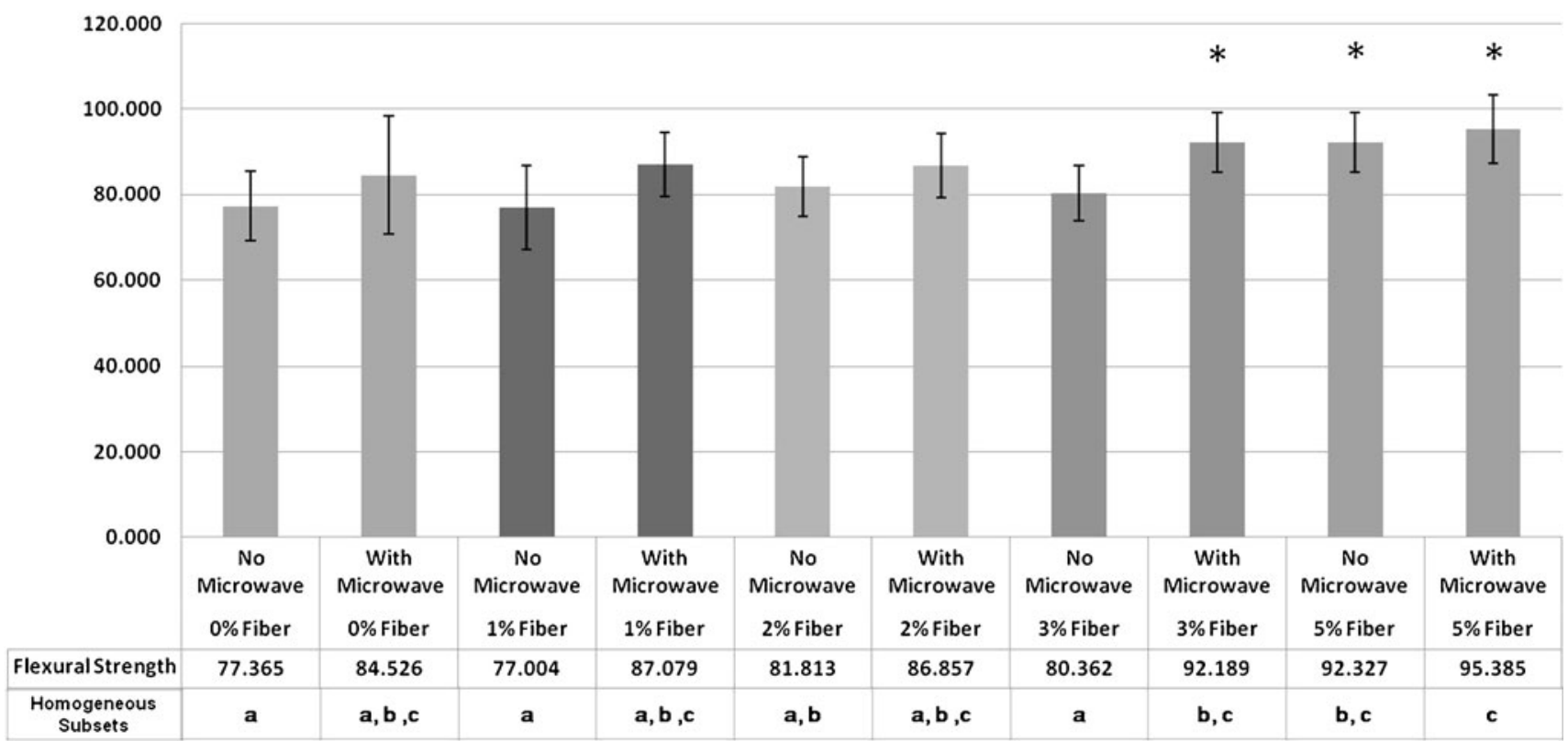

Fig. 1 The mean values of flexural strength of test specimens reinforced with various \% of fiber and microwave treatment after storage at room temperature and humidity for 1 day. Asterisk $(*)$ represents the group with significant difference with the control group, i.e. $0 \%$ fiber and no microwave treatment. The same letter $(a, b, c)$ in the homogeneous subsets table represents that the test groups were not significantly different $(p>0.05)$

Flexural Strength (MPa)

Flexural Strength of Specimen Stored at Room Temperature and Humidity for 7 Days

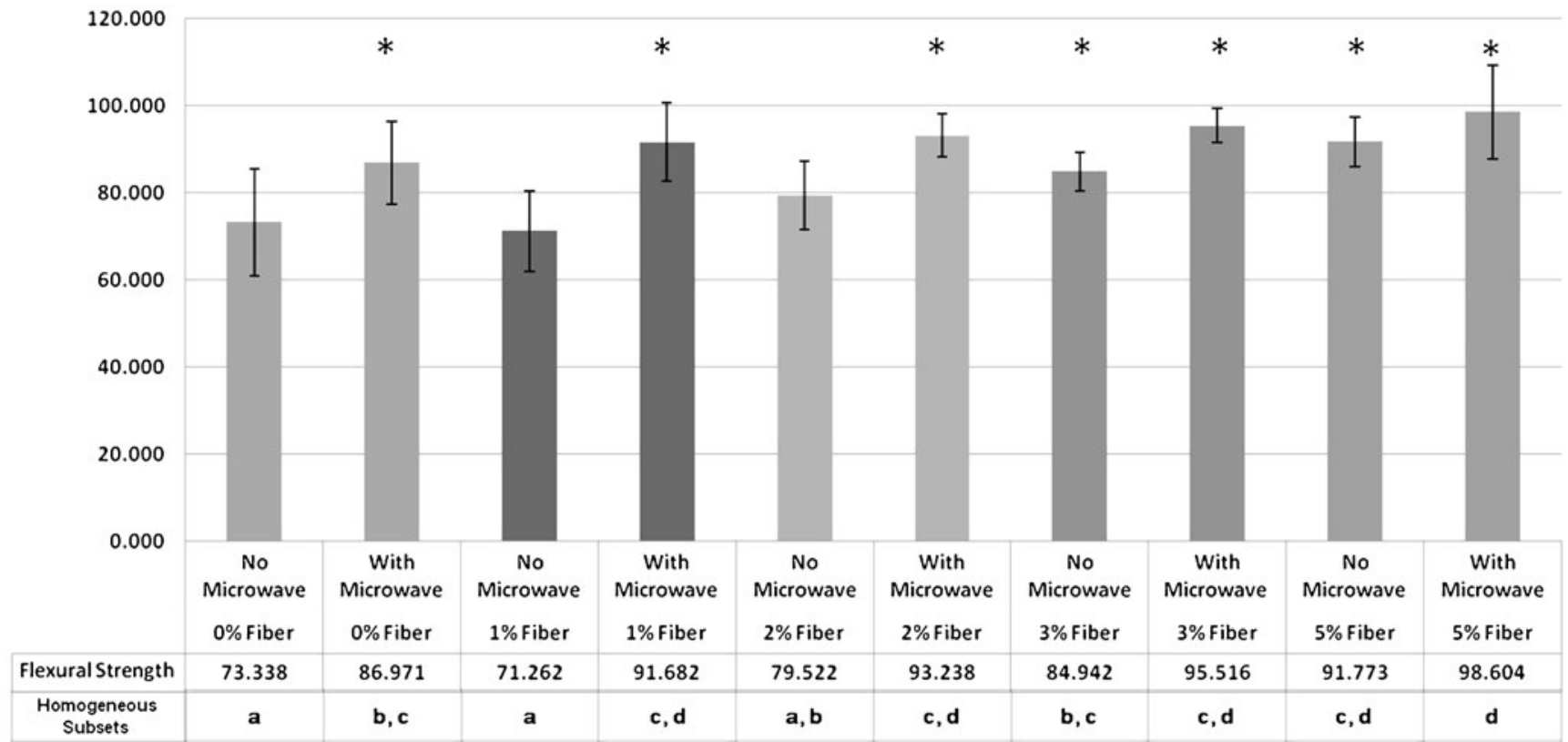

Fig. 2 The mean values of flexural strength of test specimens reinforced with various \% of fiber and microwave treatment after storage at room temperature and humidity for 7 days. Asterisk $(*)$ represents the group with significant difference with the con- trol group, i.e. $0 \%$ fiber and no microwave treatment. The same letter $(a, b, c, d)$ in the homogeneous subsets table represents that the test groups were not significantly different $(p>0.05)$ 


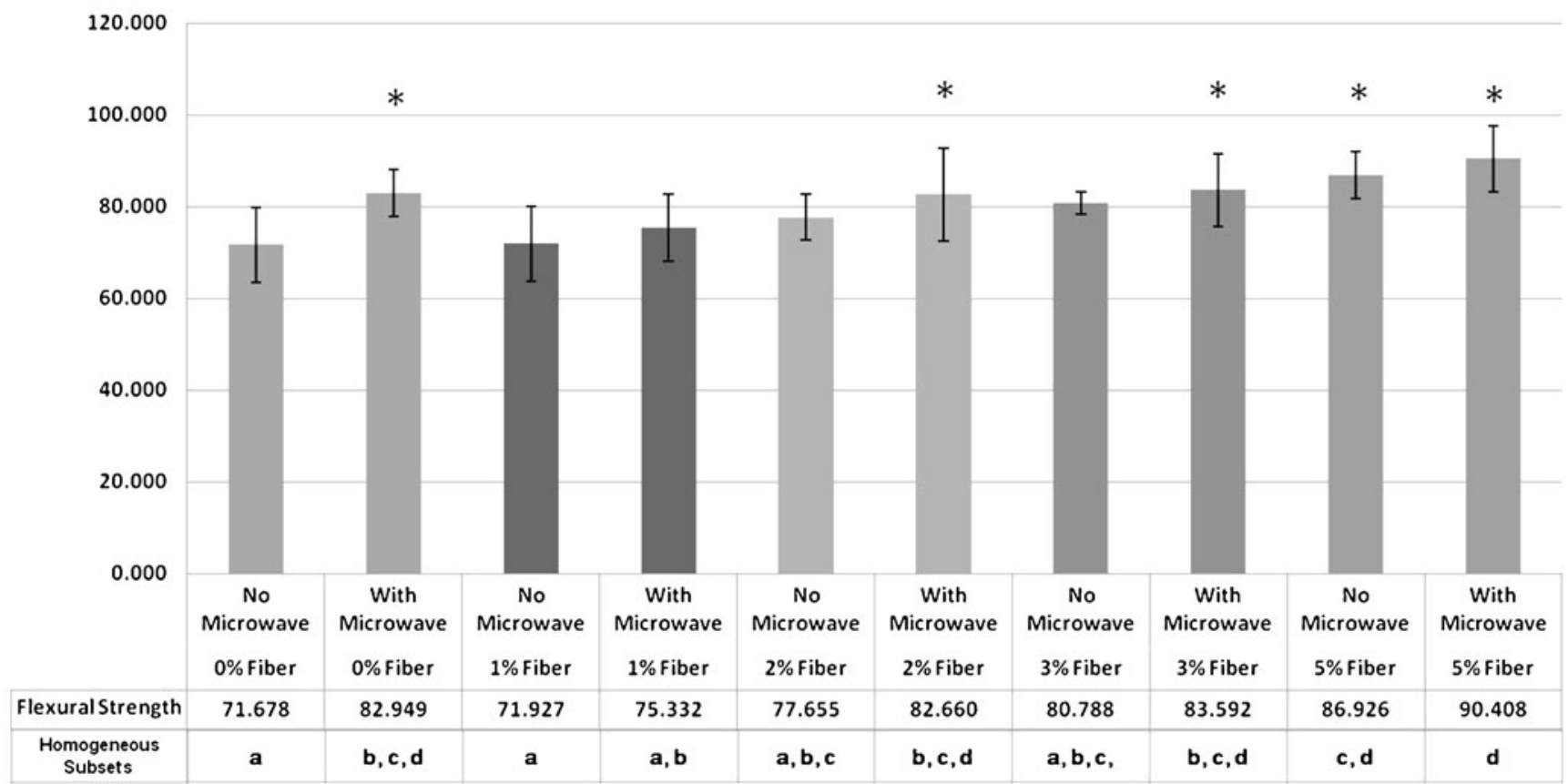

Fig. 3 The mean values of flexural strength of test specimens reinforced with various \% of fiber and microwave treatment after 7 days water storage. Asterisk (*) represents the group with significant difference with the control group, i.e. $0 \%$ fiber and no microwave treatment. The same letter $(a, b, c, d)$ in the homogeneous subsets table represents that the test groups were not significantly different $(p>0.05)$

Flexural Strength (MPa)

Flexural Strength of Specimen after Water Storage for 14 Days

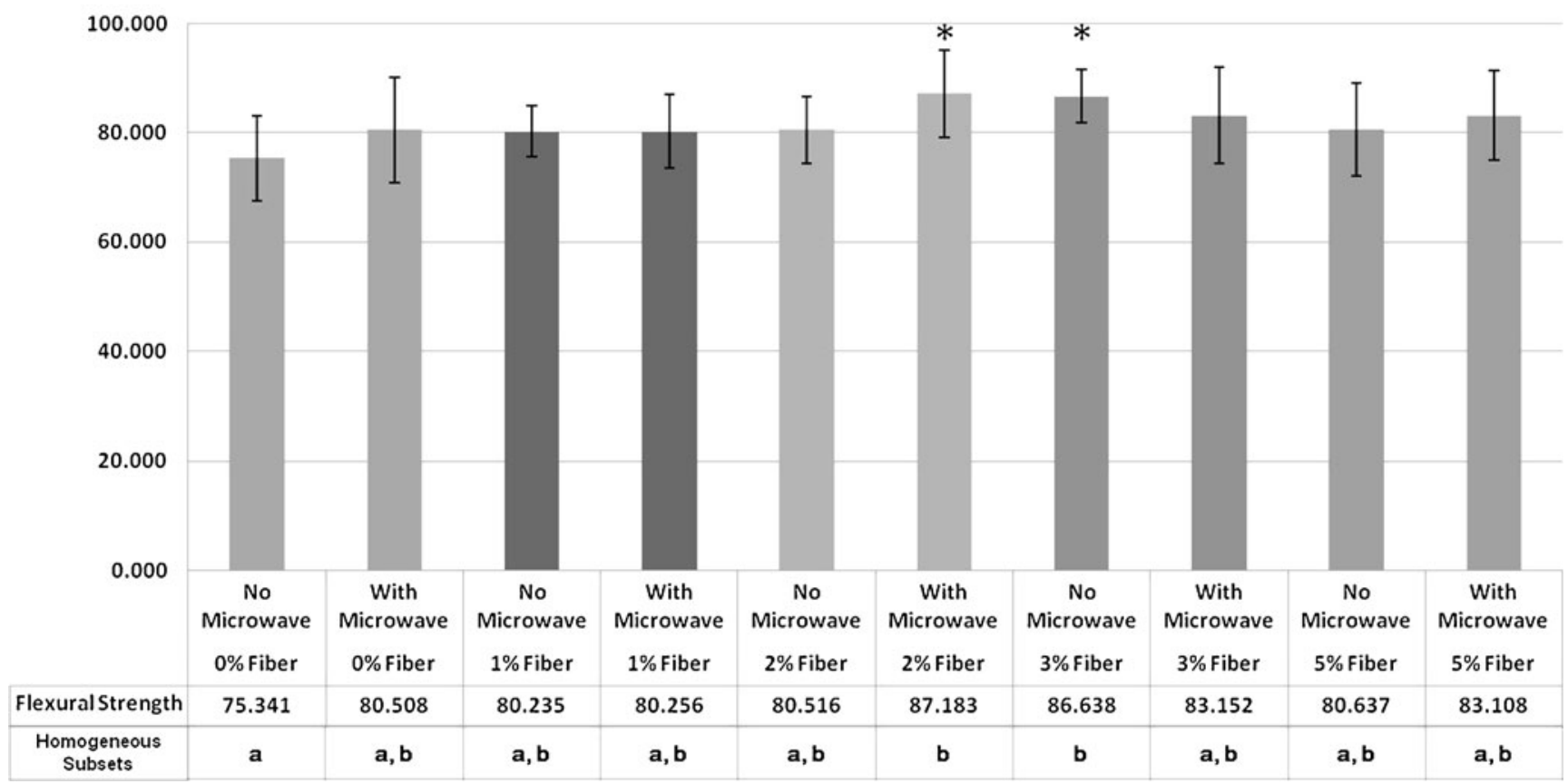

Fig. 4 The mean values of flexural strength of test specimens reinforced with various \% of fiber and microwave treatment after 14 days water storage. Asterisk (*) represents the group with significant difference with the control group, i.e. $0 \%$ fiber and no microwave treatment. The same letter $(a, b)$ in the homogeneous subsets table represents that the test groups were not significantly different $(p>0.05)$ 


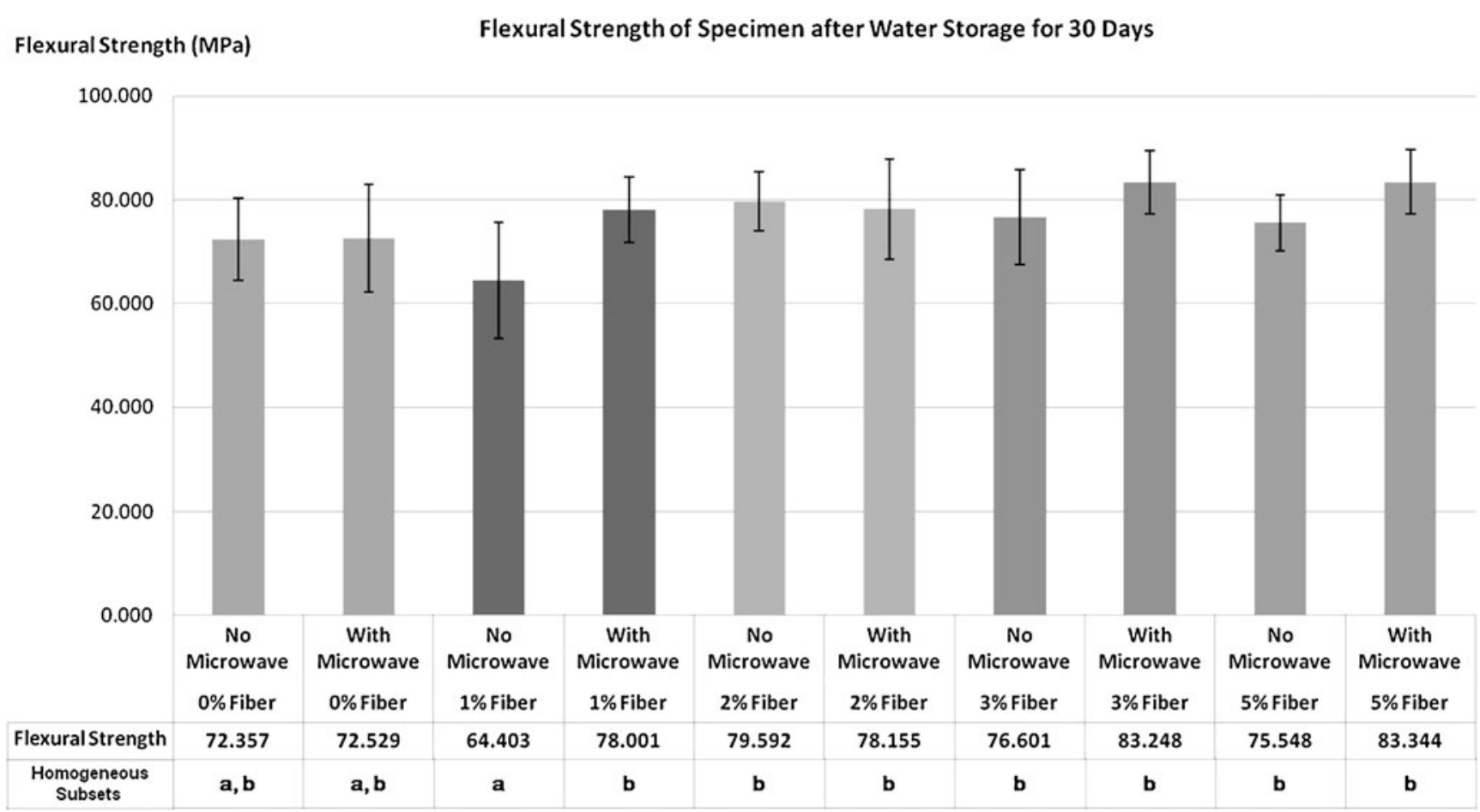

Fig. 5 The mean values of flexural strength of test specimens reinforced with various \% of fiber and microwave treatment after 30 days water storage. Asterisk (*) represents the group with significant difference with the control group, i.e. $0 \%$ fiber and no microwave treatment. The same letter $(a, b)$ in the homogeneous subsets table represents that the test groups were not significantly different $(p>0.05)$

The effects of fiber concentration and post-curing microwave irradiation on the flexural strength of different test groups compared by 2-way ANOVA are summarized in Table 4. The results of 2-way ANOVA showed that both fiber concentration and microwave treatment had significant effects on the reinforcement of cold-cured PMMA under storage at room temperature and humidity for 1 day and 7 days, and water storage for 7 days $(p<0.001)$. However, when the length of water storage time increased to 14 days, the effect of fiber remained $(p<0.05)$ but the effect of microwave treatment vanished $(p>0.05)$. After 30 days water

Table 4 The summary of 2-way ANOVA

\begin{tabular}{|c|c|c|c|c|c|}
\hline Factor & $\begin{array}{l}\text { Storage at room } \\
\text { temperature } \\
\text { and humidity } \\
\text { for } 1 \text { day }\end{array}$ & $\begin{array}{l}\text { Storage at room } \\
\text { temperature } \\
\text { and humidity } \\
\text { for } 7 \text { days }\end{array}$ & $\begin{array}{l}7 \text { days in water } \\
\text { storage }\end{array}$ & $\begin{array}{l}14 \text { days in } \\
\text { water storage }\end{array}$ & $\begin{array}{l}30 \text { days in } \\
\text { water storage }\end{array}$ \\
\hline $\begin{array}{l}\text { Fiber } \\
\text { concentration }\end{array}$ & $\begin{array}{l}\text { Significant } \\
\quad(p<0.001)\end{array}$ & $\begin{array}{l}\text { Significant } \\
\quad(p<0.001)\end{array}$ & $\begin{array}{l}\text { Significant } \\
\quad(p<0.001)\end{array}$ & $\begin{array}{l}\text { Significant } \\
\quad(p=0.020)\end{array}$ & $\begin{array}{l}\text { Significant } \\
\quad(p<0.001)\end{array}$ \\
\hline Microwave & $\begin{array}{l}\text { Significant } \\
\qquad(p<0.001)\end{array}$ & $\begin{array}{l}\text { Significant } \\
\qquad(p<0.001)\end{array}$ & $\begin{array}{l}\text { Significant } \\
\qquad(p<0.001)\end{array}$ & $\begin{array}{l}\text { Not Significant } \\
\quad(p=0.132)\end{array}$ & $\begin{array}{l}\text { Significant } \\
\qquad(p=0.001)\end{array}$ \\
\hline $\begin{array}{l}\text { Interaction of fiber } \\
\& \text { microwave }\end{array}$ & $\begin{array}{l}\text { Not Significant } \\
\quad(p=0.419)\end{array}$ & $\begin{array}{l}\text { Not Significant } \\
\quad(p=0.094)\end{array}$ & $\begin{array}{l}\text { Not Significant } \\
\quad(p=0.237)\end{array}$ & $\begin{array}{l}\text { Not Significant } \\
\quad(p=0.176)\end{array}$ & $\begin{array}{l}\text { Significant } \\
\quad(p=0.017)\end{array}$ \\
\hline
\end{tabular}


Fig. 6 SEM micrographs from the fracture surfaces of specimen without microwave treatment and stored at room temperature and humidity for 1 day (a with $1 \%$ fibers; b with $2 \%$ fibers; c with $3 \%$ fibers; d with $5 \%$ fibers).

Note the good impregnation of the fibers into the PMMA matrix. Magnification: $500 \times$
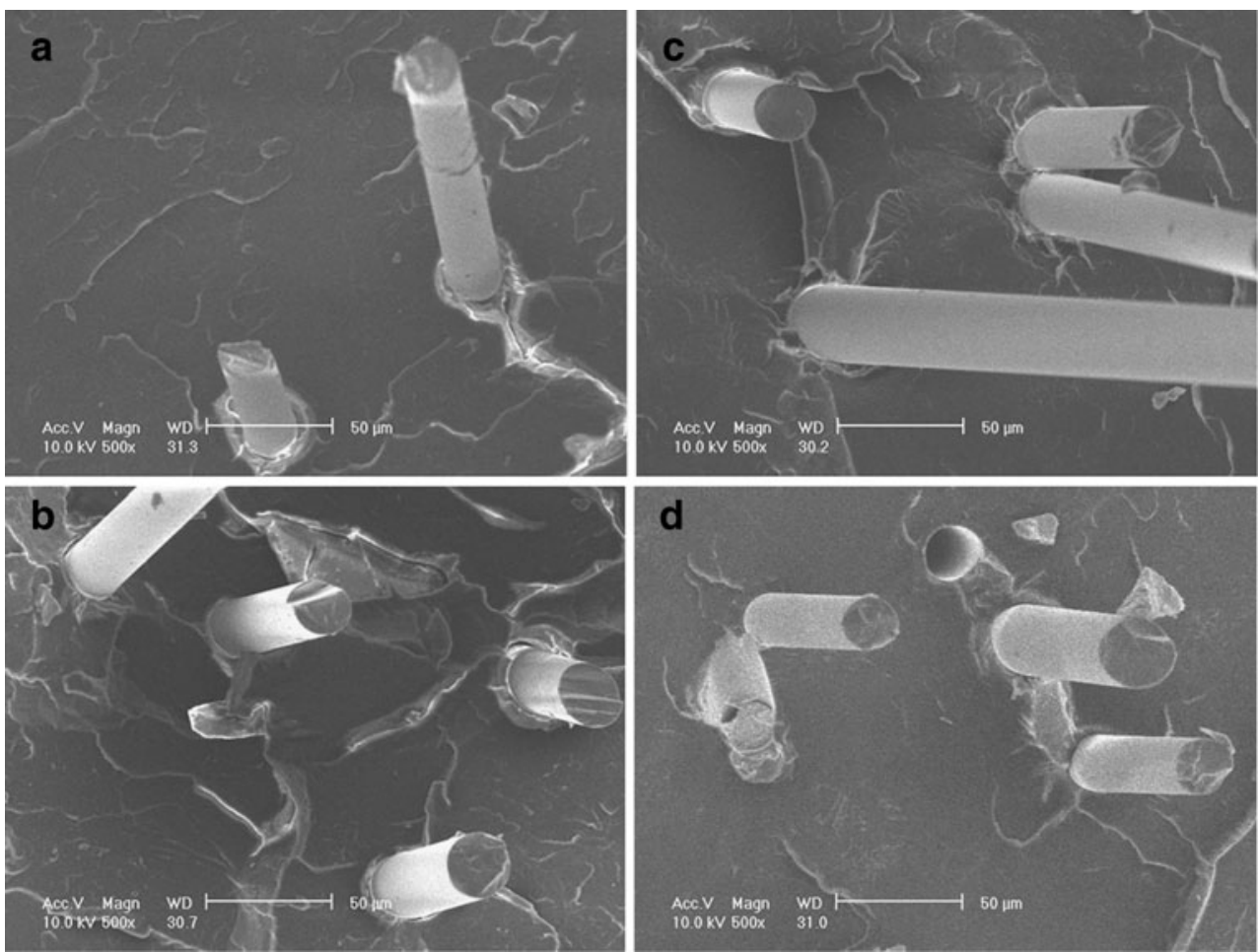

storage, fiber concentration and microwave treatment had significant effects $(p<0.05)$ contributed to the flexural strength, however, no test groups exhibited any significant reinforcement effect. The result of 2-way
ANOVA further showed that there was no significant interaction between the fibers and the microwave irradiation for all storage conditions except when in storage for 30 days $(p=0.017)$.
Fig. 7 SEM micrographs from the fracture surfaces of specimen without microwave treatment and stored at room temperature and humidity for 1 day (a with $1 \%$ fibers; b with $2 \%$ fibers; c with $3 \%$ fibers; d with $5 \%$ fibers). Arrow 1: A fiber pulled out from the crack surface. Arrow 2: A fiber pulled-out hole. Note how the chopped fibers are randomly orientated. Magnification: $100 \times$
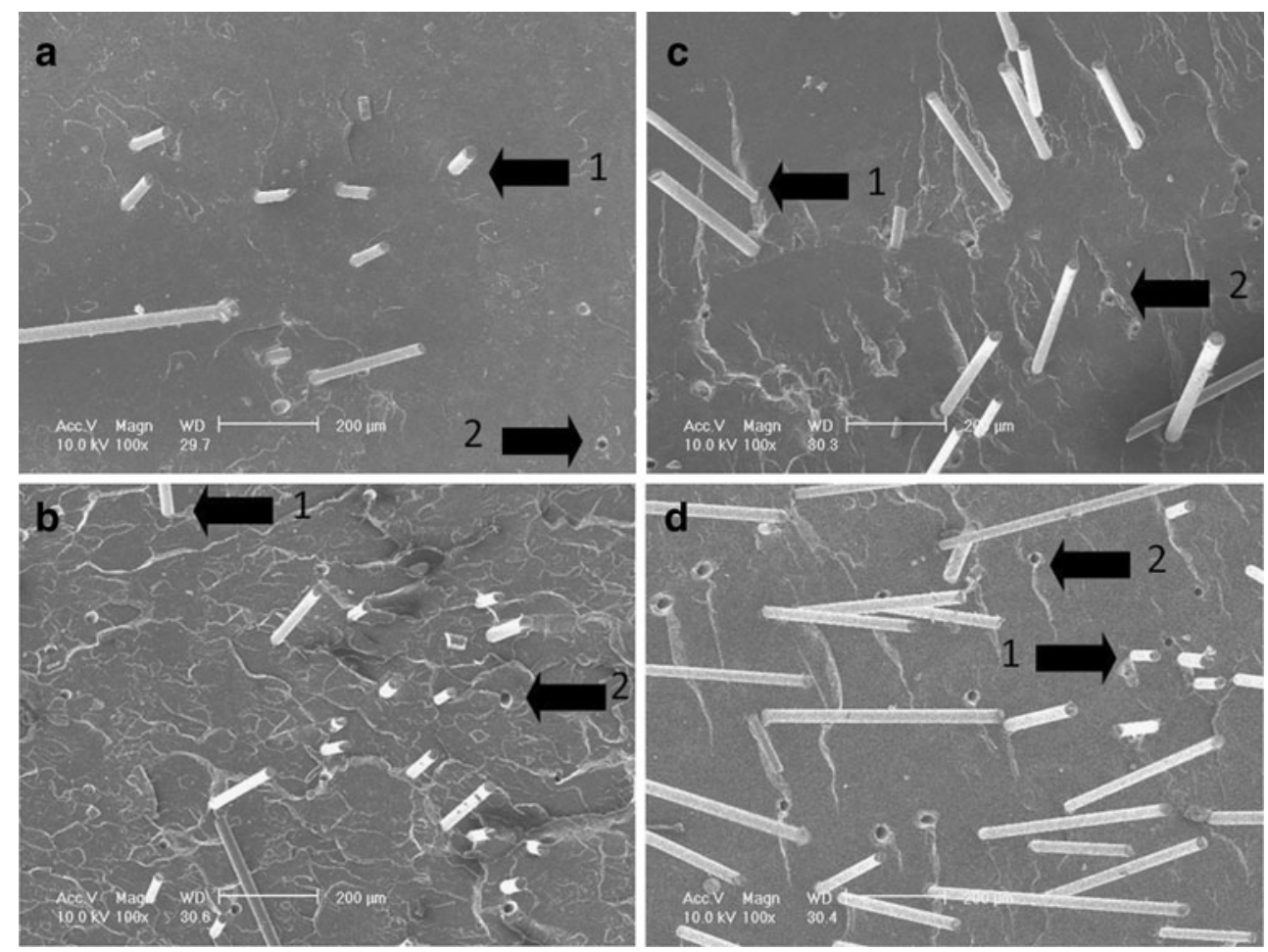
The SEM micrographs of fracture surface clearly showed that there was no void formation around the fibers (Fig. 6) and the specimens had an even distribution of fibers (Fig. 7).

\section{Discussion}

The results of this study suggested that the combination of chopped E-glass fibers and post-curing microwave irradiation might yield a stronger reinforcement than the standalone method. The achieved reinforcement in this study is also superior to other studies involving chopped glass fibers to reinforce PMMA using a compression molding method in specimen preparation and under the same storage conditions [22,24]. Despite the outcome that there was no reinforcement of cold-cured PMMA after 30 days in water storage for all test groups, the group with a $2 \%$ fiber concentration and treated with the post-curing microwave irradiation was demonstrated to deliver reinforcement in a consistent trend that has the reinforcing ability at room temperature and humid conditions (Fig. 2), after water storage for 7 days (Fig. 3) and for 14 days (Fig. 4).

For the test groups with fiber concentration higher than $2 \%$, the reinforcing capacity was shown to disappear after 14 days water storage. This may be due to the higher fiber content in the acrylic resin; i.e. more glass fibers are proximal to the surface which is more vulnerable to hydrolytic degradation [38] which, on the other hand, may leach out boron oxide $\left(\mathrm{B}_{2} \mathrm{O}_{3}\right)$ and lead to the formation of "micro-void" spaces in the PMMA specimen. These "micro-void" spaces created during water storage lowered the mechanical properties of the PMMA and outweigh the reinforcement effect by the glass fibers. Therefore, PMMA reinforced with a $2 \%$ fiber concentration and treated with post-curing microwave irradiation seemed to be the most effective combination to reinforce cold-cured PMMA.

However, the number of groups with reinforcement ability declines upon water storage for 7 days and only 2 groups exhibited the ability to reinforce the cold-cured PMMA after 14 days in water storage. This suggests that water has an adverse effect on the reinforcing power of E-glass fibers. In fact, the very small water molecules are able to penetrate into the PMMA due to the polar group present in the molecular structure of PMMA [9], and the water may cause hydrolytic degradation of the glass fibers and leach out the $\mathrm{B}_{2} \mathrm{O}_{3}$ from the fiber surface. Thus, the strength of glass fibers is reduced [38].

The water storage time was set at the maximum of 30 days because it has been reported in an in vitro study that reduction in flexural properties of glass fiber reinforced PMMA occurred during the first 4 weeks of storage in water and remained approximately at that level for 180 weeks [39]. Thus, the effect of 30 days water storage on the flexural strength of glass fiber reinforced PMMA could reflect the flexural strength after long term water storage. However, in the oral environment, the reinforced PMMA is subjected to the interaction with components from complexity such as diet, saliva and body enzymes. Hence, the reinforcement by the glass fibers may be further reduced.

It has been reported that in the case of an epoxy resin reinforced with glass fibers, there was interaction between microwave irradiation and glass fiber reinforcement which leads to stronger bonding at the fiber/matrix interphase [37]. However, in the current study, the 2-way ANOVA has rejected the presence of interaction between the fibers and the microwave treatment in the storage conditions where a reinforcement effect was observed (i.e. for storage at room temperature and at ambient humidity, water storage in 7 days and 14 days) under the treatment conditions, i.e. the fiber concentration, power and time of microwave irradiation employed in this study. Therefore, there was no improvement in bonding between the fibers and the PMMA matrix after the microwave irradiation.

When chopped glass fibers are applied to reinforce PMMA, some previous studies described the procedure of using of a "minimum" amount of MMA liquid to wet the glass fibers, and then mix the wetted glass fibers with the resin powder [22, 24]. In fact, the suggestion to use MMA liquid to wet the glass fibers was advised in the instructions of use by the manufacturer [22, 24]. Two noteworthy issues emerged when such a procedure was followed: firstly, the "minimum" amount of MMA would immediately be absorbed by the bulk mass of resin powder. Hence, the glass fibers could not be dispersed throughout the resin matrix but they would rather aggregate, to form fiber clusters. The inner cores of such aggregated glass fibers were impossible to be embedded into the viscous resin-monomer matrix, and resulted in a poor impregnation and this compromised the biomechanical properties accordingly. By using compression molding, an uneven distribution of glass fibers and voids surrounding the glass fibers (as seen in the SEM image from another study) has substantiated this problem [22]. Another issue of using some extra MMA to wet the glass fibers is the concern of residual monomers released from the PMMA and the potential allergy responses of the patient [40]. This is why some other monomers have been investigated as alternative options [35]. 
To solve the first issue mentioned above, it was suggested to use injection molding instead of compression molding to fabricate the acrylic dental appliances. Promising results in terms of transverse strength and impact strength, as well as desirable fiber impregnation, were obtained [22]. However, in the fabrication of orthodontic removable appliances, where the so-called "sprinkle technique" is employed, injection molding may not be applicable. In the present study, a new mixing method in which the chopped glass fibers are pre-wetted by some MMA liquid, and then the resin powder was added in small increments to form a semisolid mixture, was developed. The SEM images (Figs. 6 and 7) suggested that a good fiber impregnation was achieved. Another advantage is that no extra monomer was needed. The sample preparation may not be perfect i.e. it is always a matter of the operator, but we may claim it is at least a workable formulation and method for a dentist or a dental technician to use glass fiber mixing into commercial cold-cured acrylic, without a change of procedure.

The E-glass fibers were pre-treated with a silane coupling agent during the manufacturing. Theoretically, such a design may allow a chemical bonding to be formed between the fibers and the PMMA matrix. However, as seen in the SEM images of the fracture surfaces (Figs. 6 and 7), the surface of the pulled-out glass fiber was very smooth. This implies the bonding between the glass fibers and the PMMA matrix was not adequate enough. A better bonding between glass fibers and the resin matrix might be carried by pre-impregnation of glass fibers with a thermoplastic polymer. The porous structure in the polymer pre-impregnated glass fibers enables the matrix to obtain both mechanical and chemical bonding. When pre-impregnated glass fibers are used, it is expected that there will be a greater reinforcement effect [32].

In the current study all microwave post-cured results showed higher flexural strength values than the nonmicrowave treated analogues at room temperature and at ambient humidity (Figs. 1 and 2). It has been reported that post-curing microwave irradiation could reduce the amount of residual monomers [41]. Although the report did not find out the underlying reason, nor residual monomer analysis such as chromatography was not conducted in the current study, the specimens were treated solely with the microwave irradiation. The exhibited reinforcement effect was probably due to the irradiated heat which subsequently polymerizes the resin into a higher degree by reducing the residual monomers. It might be useful to determine the exact mechanism and the degree of polymerization in the glass fiber impregnated and microwave irradiated PMMA in the near future.

When the microwave irradiation is applied, there are a couple of precautions: firstly, higher power and longer irradiation time provide more heat that reduces the amount of residual monomers and improves the mechanical properties of the resin. However, overexposure of microwave irradiation will cause the color change of the specimen which maybe an aesthetic issue. For microwave irradiation of more than $3 \mathrm{~min}$, the specimens become white in color and at the same time lose their transparency. When the microwave irradiation was set to $5 \mathrm{~min}$, the specimens even turned brownish or yellowish. Thus, the microwave irradiation time in the current study was set to $3 \mathrm{~min}$. Secondly, the container holding the specimen also matters. A glass beaker was once used to hold the specimen into the microwave oven and a color change of the specimen occurred in $3 \mathrm{~min}$ of irradiation. It is possibly due to the better retention of atmospheric moisture on the surface of the glass beaker which may generate some extra heat due to the interaction between moisture and the microwaves. Therefore, a dry microwavable plastic container is recommended for use. Thirdly, the number of specimens placed into the microwave oven will affect the quality of irradiation. If too many specimens were placed into the microwave oven, the polymerization (an exothermic reaction) heat generated in each specimen would accumulate and a very high ambient temperature would be generated locally. It was also observed that there was a color change of specimens (white color and loss of transparency) after 3 min of irradiation when too many specimens were processed in one go. This may be due to the chemical change of components in the PMMA resin and the oxidation of the polymerization reaction activator, a tertiary amine $N, N$-dimethyl- $p$ toluidine which produces a yellow color upon oxidation [42]. Therefore, in the current study, the microwave irradiation was processed in 2 microwavable plastic containers that held 6 specimens (i.e. 3 specimens in each plastic container) for 3 min each time.

There might be some limitations in the current study to bear in mind. Firstly, only a domestic microwave oven was employed and it had been reported that there was fluctuation of power in a domestic microwave oven [43]. Thus, there might be variations in the irradiation quality of specimens. However, it may not be costeffective to employ an industrial microwave oven in the study even at the dental clinic or laboratory. Secondly, the E-glass fibers were chopped manually in this study. This may have resulted in the damaged silane coating in the proximity of the cut surfaces of the chopped fibers (i.e. the surfaces on 2 heads of the individual chopped 
fiber). These unsilanized cut surfaces on the chopped glass fibers had no chemical bonding to the PMMA matrix and thus may have lead to the weakening. To minimize this problem, adequate spreading of the chopped fibers is required to avoid the accumulation of the unsilanized cut surfaces to form a large glass fiber/PMMA interphase where no chemical bonding is available, if manual chopping was performed. Thirdly, strictly speaking, the used equation (1) is actually applicable to linear elastic behavior. In the groups without reinforcement or microwave treatment, the material behavior is nonlinear and this might have lead to an overestimation of the flexural strength measured. Using a uniaxial tensile test might be an option for the near future studies with similar type of testing set-up.

Hence the bonding between the chopped glass fibers and the PMMA matrix was probably not adequate. Future studies could be conducted to improve the adhesion between the fibers and the matrix in the aspects of the silane to achieve a stronger chemical bonding, and of the usage of pre-impregnated glass fibers to obtain mechanical retention between the fibers and the matrix. In this regard, not only the adhesion between the fibers and the matrix could be studied, but also the effects of increased hydrophobicity of the glass fibers which might alter the susceptibility to hydrolytic degradation.

\section{Conclusions}

1. Within the concentration of chopped E-glass fibers in $3 \mathrm{~mm}$ and time and power of the microwave irradiation, the incorporation of chopped E-glass fibers in combination with a post-curing microwave irradiation resulted in a significant increase in the flexural strength of the cold-cured PMMA.

2. The reinforcement effect delivered by the incorporation of chopped E-glass fibers and post-curing microwave irradiation diminished as the number of days kept in water storage was increasing.

3. The most effective combination of treatments to obtain a significant increase in flexural strength was $2 \%$ (wt. to the resin) fiber concentration with postcuring microwave irradiation. A consistent trend of the reinforcement effect in water storage at $37^{\circ} \mathrm{C}$ was produced and the reinforcement effect lasted for 14 days.

4. Finally, as an outcome, a new mixing method which might be applicable with the "sprinkle method" in the fabrication of orthodontic removable appliances was successfully developed.
Acknowledgements The authors wish to thank Stick Tech Ltd. (Turku, Finland) for generously providing the E-glass fibers to this study, that was also a part of the MSc(DMS) studies of the first author. We also appreciate and acknowledge the valuable comments from the reviewers.

Open Access This article is distributed under the terms of the Creative Commons Attribution License which permits any use, distribution, and reproduction in any medium, provided the original author(s) and the source are credited.

\section{References}

1. Winkler S (1984) Dent Clin N Am 28(2):287

2. Peyton FA (1975) Dent Clin N Am 19(2):211

3. Darvell BW (2006) Materials science for dentistry, 8th edn. Hong Kong

4. Powers JM, Wataha JC (2008) Dental materials: properties and manipulation, 9th edn. Mosby/Elsevier, USA, p 285

5. Kostoulas I, Kavoura VT, Frangou MJ, Polyzois GL (2008) J Prosthodont 17(4):257

6. Murata H, Seo RS, Hamada T, Polyzois GL, Frangou MJ (2007) J Prosthet Dent 98(4):319

7. Roberts-Harry D, Sandy J (2004) Br Dent J 196(1):9

8. van Noort R (2007) Introduction to dental materials. Mosby/Elsevier, USA, p 43

9. Bettencourt AF, Neves CB, de Almeida MS, Pinheiro LM, Oliveira SA, Lopes LP, Castro MF (2010) Dent Mater 26(5):e171

10. Sun J, Yu YC, Liu MY, Chen L, Li HW, Zhang L, Zhou Y, Ao D, Tao R, Lai WL (2011) J Dent Res 90(10):1197

11. Rodford R (1986) J Dent 14(5):214

12. Jagger DC, Harrison A, Jandt KD (1999) J Oral Rehabil 26(3):185

13. Carroll CE, von Fraunhofer JA (1984) J Prosthet Dent 52(5):639

14. Jennings RE, Wuebbenhorst AM (1960) J Dent Child 27:162

15. Vallittu PK (1993) J Oral Rehabil 20(3):241

16. Vallittu PK, Lassila VP (1992) J Oral Rehabil 19(4):385

17. Yazdanie N, Mahood M (1985) J Prosthet Dent 54(4):543

18. Chen SY, Liang WM, Yen PS (2001) J Biomed Mater Res 58(2):203

19. Foo SH, Lindquist TJ, Aquilino SA, Schneider RL, Williamson DL, Boyer DB (2001) J Prosthodont 10(3):148

20. Vallittu PK (1997) Dent Mater 13(6):381

21. Chow TW, Cheng YY, Ladizesky NH (1993) J Dent 21(6):367

22. Karacaer Ö, Polat TN, TezvergIl A, Lassila LVJ, Vallittu PK (2003) J Prosthet Dent 90(4):385

23. Kim SH, Watts DC (2004) J Prosthet Dent 91(3):274

24. Stipho HD (1998) J Prosthet Dent 79(5):580

25. Uzun G, Hersek N, Tinçer T (1999) J Prosthet Dent 81(5):616

26. Vallittu PK (1996) J Prosthodont 5(2):115

27. Vallittu PK, Lassila VP, Lappalainen R (1994) Dent Mater 10(2):116

28. Vallittu PK, Narva K (1997) Int J Prosthodont 10(2):142

29. Zhang M, Matinlinna JP (2012) Silicon 4(1):73

30. Matinlinna JP, Lassila LV, Ozcan M, Yli-Urpo A, Vallittu PK (2004) Int J Prosthodont 17(2):155

31. Vallittu PK (1993) J Oral Rehabil 20(5):533

32. Narva KK, Lassila LVJ, Vallittu PK (2005) Compos Part A: Appl S 36(9):1275

33. Vallittu PK (1999) J Prosthet Dent 81(3):318 
34. McOrmond A (1996) Orthodontic laboratory techniques, Ch 5. WD Publishing, Canada, p 16

35. Zhang M, Matinlinna JP (2011) J Adhes Sci Technol 25:2687

36. Faltermeier A, Rosentritt M, Müssig D (2007) Am J Orthod Dentofacial Orthop 131(3):301.e16

37. Thostenson ET, Chou TW (1999) Compos Part A: Appl S 30(9):1055

38. Vallittu PK, Ruyter IE (1998) Int J Prosthodont 11(4):340

39. Vallittu PK (2000) Int J Prosthodont 13(4):334
40. Jorge JH, Giampaolo ET, Machado AL, Vergani CE (2003) J Prosthet Dent 90(2):190

41. Urban VM, Machado AL, Oliveira RV, Vergani CE, Pavarina AC, Cass QB (2007) Dent Mater 23(3):363

42. Bonatti MR, Cunha TR, Regis RR, Silva-Lovato $\mathrm{CH}$, Paranhos HF, de Souza RF (2009) J Prosthodont 18(5): 432

43. Kok LP, Visser PE, Boon ME (1994) J Neurosci Methods 55(2):119 